\title{
Advanced glycation in diabetes, aging and age-related diseases: conclusions
}

\author{
Vincent M. Monnier ${ }^{1} \cdot$ Naoyuki Taniguchi $^{2}$ \\ Published online: 16 July 2016 \\ (C) Springer Science+Business Media New York 2016
}

\section{Conclusions}

What have we learned from the above articles? Several lessons. First, perhaps the single most important message that is confirmed here is that tissue and fluid levels of advanced glycation end products are robustly linked to metabolic imbalance and the associated disease progression risk, as in diabetes and obesity. This is key to future research on the Maillard Reaction in vivo, otherwise there would be no reasons to worry about AGE chemistries, sources and turnover rate, signaling mechanisms, technological improvements and, above all, designing novel pharmaceutical strategies to prevent the deleterious effects of AGEs. This leads us to the key question of whether pharmacological therapy of elevated AGE levels will ameliorate disease outcome. As reviewed by Forbes et al. this strategy worked amazingly well in numerous rodent experiments, but results were much less robust, if not altogether equivocal, in humans with diabetes. There are various reasons for this and perhaps the novel approach proposed by Thornalley and colleagues, i.e. improving glyoxalase activity by acting on its transcription factor Nrf2 will offer greater promise. Paradoxically, however, one might never entirely know whether any beneficial effect from such approach will be the result from improved dicarbonyl or oxidative stress. This is one reason why sophisticated high throughput quanti-

Vincent M. Monnier

vmm3@cwru.edu

1 Case Western Reserve University, Cleveland, OH, USA

2 RIKEN, Wako, Saitama, Japan

tation and imaging technologies will be needed to determine which patients are expected to respond, and which patients will be resistant to any treatment.

Only briefly covered in this issue is the critical question of the systemic effects of dietary AGEs/glycotoxins, a field pioneered by Helen Vlassara and her group. Piperi, Boulanger and their respective colleagues each kindly contributed a paper to this issue and the reader is referred to the appropriate literature for further information. This relatively novel research direction in the field of the Maillard Reaction is, in our view, of critical importance for the understanding of the "gene environment" paradigm. We can tentatively place the risk of heating highly heat processed foods in the same category of health risks as elevated levels of blood cholesterol, blood pressure, smoking, sedentariness, UV light exposure, or environmental toxins: all have in common that they do not exert perceivable damage for many years, until it is too late. They also have in common that some people are more susceptible to these insults than others, often for yet unclear reasons. The main difference to date is that, while the other risk factors have all been proven in multiple studies, research on the biomedical effects of heat processed foods is in its infancy and long-term research in the human with links to genetics and the microbiome will be needed to rapidly determine who is at risk and what kind of food AGEs are toxic to humans.

Looking at the broader picture, enormous progress in our understanding of the Maillard Reaction in vivo and in food science was achieved ever since the First International Symposium on the Maillard Reaction was held in 1989 in Udevalla. The reader is advised to consult the proceedings of the past symposia as these often contain unique and embedded information that is otherwise not easily accessible via electronic means. A complete list is provided below (1-14).

Vincent M Monnier and Naoyuki Taniguchi 


\section{References}

1. Maillard Reactions in Food: In: Eriksson C. (ed.) Progress in Food and Nutrition Science, pp. 1-497. Pergamon Press, Oxford (1981)

2. Conference on Nonenzymatic Glycosylation and Browning Reactions: Their Relevance to Diabetes Mellitus. In: Peterson, C.M. (ed.), Kroc Foundation vol. Supp 3, pp. 1-82. Diabetes (1982)

3. The Maillard Reaction in Foods and Nutrition. In: Waller, G.R., Feather, M.S. (ed.), Las Vegas. ACS Symp. Ser., pp. 1-565. American Chemical Society (1983)

4. Amino-Carbonyl Reactions in Food and Biological Systems. In: Fujimaki, M., Namiki, M., Kato, H. (eds.) Proceeding of the 3rd International Symposium on the Maillard Reaction, Fuji Institute, Susono, Shizuoka. Developments in Food Science, pp. 1-579. Kodanska Ldt. Elsevier (1986)

5. The Maillard Reaction in Aging, Diabetes and Nutrition. In: Baynes, J.W., Monnier, V.M. (eds.), Bethesda. Prog. Clin. Biol. Res. Alan R. Liss, NY (1989)

6. The Maillard Reaction in Food Processing, Human Nutrition and Physiology. In: Finot, P.A., Aeschbacher, H.U., Hurrell, R.F., Liardon, R. (eds.), Nestle Research Center, Switzerland. Advances in Life Sciences, pp. 1-511. Birkhaeuser Verlag (1990)

7. Glycated Proteins in Diabetes Mellitus. In: Ryall, R.G. (ed.) Proceedings of an International Symposium, Adelaide, Adelaide, South Australia 1990, pp. 1-323. University of Adelaide Press (1988)

8. Maillard Reactions in Chemistry, Food, and Health. In: Labuza, T.P., Reineccius, G.A., Monnier, V.M., O'Brien, J.S., Baynes, J.W. (eds.), University of Minnesota, pp. 1-435. The Royal Society of Chemistry (1994)
9. The Maillard Reaction in Food Chemistry and Medical Science: Update for the Postgenomic Era. In: Horiuchi, S., Taniguchi, N., Hayase, F., Kurata, T., Osawa, T. (eds.) The 7th International Symposium on the Maillrad Reaction, Kumamoto. Inernational Congress Series 1245. Elsevier (2002)

10. The Enzymatic Defence Against Glycation in Health, Disease and Therapeutics: a Symposium to Examine the Concept. Thornalley PJ. Biochem. Soc. Trans. Dec;31(Pt 6):1341-1342 (2003)

11. The Maillard Reaction: Chemistry at the Interface of Nutrition, Aging and Disease. In: Baynes, J.W., Monnier, V.M., Ames, J.M., Thorpe, S.R. (eds.) Eighth International Symposium on the Maillard Reaction, Charleston, South Carolina. Annals of the New York Academy of Sciences, pp. 1-949. The New York Academy of Sciences (2005)

12. The Maillard Reaction: Recent Advances in Food and Biomedical Sciences. In: Schleicher, E., Somoza, V., Schieberle, P. (eds.) 9th International Symposium on the Maillard Reaction, Munich. Annals of the New York Academy of Sciences, pp. 1-337. The New York Academy of Sciences (2008)

13. The Maillard Reaction: Interface between aging, Nutrition and Metabolism. In: Thomas M C., and Forbes, J. (eds). 10th International Symposium on the Maillard Reaction, Palm Cove. The Royal Society of Chemistry, Cambridge, UK (2009)

14. Frontiers in research on the Maillard reaction in aging and chronic diseases. In: Baynes, J.W., Gillery, P. (eds.) The 11th International Symposium on the Maillard Reaction: The Maillard Reaction at the Intersection between Food Chemistry, Butrition and Age-Related Diseases, Nancy. Clin. Chem. Lab. Med., vol. 1, pp. 1-168. Walter de Gruyter (2014) 